\title{
Long-term Results From a Randomized Controlled Trial to Increase Cancer Screening Among Attendees of Community Health Centers
}

\author{
Richard G. Roetzheim, MD, MSPH',2 \\ Lisa K. Christman, BS \\ Paul B. Jacobsen, $P b D^{2}$ \\ Jennifer Schroeder, BS ${ }^{1}$ \\ Rania Abdulla, BS ${ }^{1}$ \\ Seft Hunter, BS ${ }^{1}$ \\ 'Department of Family Medicine, \\ University of South Florida., Tampa, Fla \\ ${ }^{2} \mathrm{H}$. Lee Moffitt Cancer Center \\ \& Research Institute, Tampa, Fla
}

\begin{abstract}
PURPOSE We assessed whether increased cancer screening rates that were observed with Cancer Screening Office Systems (Cancer SOS) could be maintained at 24 months' follow-up, a period in which clinics were expected to be largely self-sufficient in maintaining the intervention.

METHODS Eight primary care clinics serving disadvantaged populations in Hillsborough County, Fla, agreed to take part in a cluster-randomized experimental trial. Charts of independent samples of established patients aged 50 to 75 years were abstracted, with data collected at baseline $(n=1,196)$ and at 24 months' follow-up ( $n=1$,296). Papanicolaou (Pap) smears, mammography, and fecal occult blood testing were assessed.
\end{abstract}

RESULTS At 24 months of follow-up, intervention patients had received a greater number of cancer screening tests (mean 1.17 tests vs 0.94 tests, $t$ test $=4.42$, $P<.0001$ ). In multivariate analysis that controlled for baseline screening rates, secular trends, and other patient and clinic characteristics, the intervention increased the odds of mammograms slightly (odds ratio [OR]) $=1.26 ; 95 \%$ confidence interval $[\mathrm{Cl}], 1.02-1.55 ; P=.03$ ) but had no effect on fecal occult blood tests $(\mathrm{OR}=1.17 ; 95 \% \mathrm{Cl}, 0.92-1.48 ; \mathrm{P}=0.19)$ or Pap smears $(\mathrm{OR}=0.88 ; 95 \%$ $\mathrm{Cl}, 0.0 .68-1.15 ; P=.34)$.

CONCLUSIONS The Cancer SOS intervention had persistent, although modest, effects on screening at 24 months' follow-up, an effect that had clearly diminished from results reported at 12 months' follow-up. Further study is needed to develop successful intervention strategies that are either self-sustaining or that are able to produce long-term changes in screening behavior.

Ann Fam Med 2005;3:109-114. DOI: 10.1370/afm.240.

\section{INTRODUCTION}

$\mathrm{P}$ atients belonging to a racial or ethnic minority are more likely to have poor cancer outcomes. ${ }^{1.7}$ Patients of low socioeconomic status and those who are uninsured or insured by Medicaid are also at greater risk of poor cancer outcomes. ${ }^{4,6,8-14}$ The reasons why these groups have less favorable cancer outcomes is not certain but has been attributed to lower rates of screening. ${ }^{15-24}$

In an attempt to address these health disparities, we developed the Cancer Screening Office System (Cancer SOS), a low-cost office systems intervention to promote screening in primary care clinics serving disadvantaged populations. The intervention is not computerized and relies on personnel and resources that are available to most primary care clinics. The intervention attempted to change systematically the behaviors of all 
office staff (including physicians) to accomplish cancer screening and is modeled after similarly successful interventions. ${ }^{25,26}$ We tested the efficacy of the Cancer SOS among patients attending community health centers, a representative setting of care for the target population.

The effectiveness of the intervention at 12 months' follow-up has been previously reported. ${ }^{27}$ In multivariate analysis that controlled for baseline screening rates, secular trends, and other patient and clinic characteristics, the intervention increased the odds of screening with mammograms (adjusted odds ratio $[\mathrm{OR}]=1.62$, $P=.023)$ and fecal occult blood tests $(\mathrm{OR}=2.5$, $P<.0001)$, with a trend toward greater use of Papanicolaou (Pap) smears $(\mathrm{OR}=1.57, \mathrm{P}=.096)$. Left unanswered, however, was whether the increased rates of screening that were observed could be sustained without ongoing support from research staff.

To assess whether the effectiveness of the intervention could be sustained, we assessed screening outcomes after an additional 12 months of follow-up, a period in which clinics were largely self-sufficient in regard to the intervention. During the first intervention year, office staff were taught how to maintain the intervention and how to train new employees in the intervention procedures. Training manuals were provided to all intervention clinics, and a person from each clinic (usually the office manager) assumed responsibility for maintaining the intervention structure. During the second follow-up year, intervention clinics were given all necessary supplies and materials but were expected to maintain the intervention themselves, without ongoing support from research staff. The durability of the intervention was assessed by chart reviews conducted at 24 months' follow-up, the results of which are reported here.

\section{METHODS}

To target an underserved population, clinics were recruited from among 16 clinics participating in a county-funded health insurance plan in Hillsborough County, Fla. Clinics were eligible for the randomized trial if (1) they provided primary medical care 5 days a week, (2) the majority of physician and other clinicians agreed to participate, and (3) the clinic was expected to continue operating in the same fashion for the next 24 months. Each clinic individually decided whether to participate in the intervention, and none was obligated to join the study. We performed a cluster-randomized experimental trial in which 8 clinics meeting eligibility criteria were randomized to either intervention or control conditions. Together the clinics provided more than 3,000 patient visits per week.

The intervention targeted 3 cancer screening tests: mammograms, Pap smears, and fecal occult blood test
(FOBT). Key components of the intervention included a cancer screening checklist that was completed by patients indicating whether patients were due for screening and a series of red, yellow, and green stickers that indicated whether recommended screening tests had been ordered and completed. Additional details about the about the clinics that participated and additional details about the intervention itself have been reported previously. ${ }^{27}$

\section{Data Collection}

During data collection periods, research assistants assembled sampling frames of all patient visits using office billing and scheduling records. Patient's records were eligible to be abstracted if both of the following criteria were met: (1) the patient was 50 to 75 years of age and (2) the patient was established in the clinic (defined as having had at least 1 visit 12 months or more before the sampled visit). Based on sample size requirements for the intervention (the intervention was structured to provide $80 \%$ power to detect increases in screening rates of $20 \%$ or more), independent random samples of 150 charts were selected for each clinic at baseline and again at 12 and 24 months after the intervention had been fully implemented in the clinic. Thus the samples were cross-sectional and did not assess the same patients during the 24-month period, as would occur in a cohort study. We also assessed compliance with the system at 6 months and again at 24 months by determining the percentage of intervention charts that contained a Cancer SOS checklist.

To prevent medical record reviews from influencing patient- or clinician-screening behavior, and to allow adequate time for recommended screening tests to be completed, we abstracted charts 3 months after study patients had visited the clinic. Neither patients nor staff were aware of the period during which chart abstractions would occur. For each of the targeted cancer screening tests, the date the procedure was completed was recorded to determine whether the patient was up-to-date on screening. We defined being up-to-date as having completed the targeted screening test during either the 12 months before the audited visit or the 3 months after the audited visit. The use of a grace period has been applied in other studies s, $28-32^{2}$ and allows sufficient time for screening tests that were recommended at an audited visit to have been completed by the patient.

Chart abstracters used a standardized method and instrument to abstract chart information and were trained by the project manager. Relevant clinical data, including progress notes, laboratory reports, radiology reports, consultation letters, and hospital records, were abstracted from all sections of the chart. Before begin- 
ning data collection, inter-rater reliability for chart abstractors was assessed for the 3 cancer screening tests by a second review of a sample of 30 charts and calculating the $\kappa$ statistic. The following values of $\kappa$ were obtained when assessing whether a patient was up-todate on cancer screening: Pap smear $\kappa=1.00$, mammogram $\kappa=1.00$, FOBT $\kappa=0.91$.

We assessed whether the patient was up-to-date on one or more of the following cancer screening tests: mammogram, Pap smear, or FOBT. Women who had a personal history of breast cancer were excluded from our analysis of mammograms. Women with a personal history of cervical cancer or those who had had a hysterectomy were excluded from our analysis of Pap smear screening. Patients with a personal history of colon cancer and those who had received a colonoscopy or double-contrast barium enema in the previous 10 years were excluded from the analysis of FOBT. We defined being up-to-date on FOBT as having completed 3 home-collected specimens, not testing a stool specimen obtained in the physician's office. For all screening outcomes, we considered only the actual completion of the screening test, not a physician's recommendation or patient refusal to be screened. Finally, all outcomes were assessed strictly by chart review, not patient's selfreport of screening on their checklist.

Approximately 850 of the charts reviewed at baseline and at 24 months did not meet eligibility criteria. For this analysis, the final data set consisted of the combined abstracted records of eligible patients from the 2 independent samples collected at baseline ( $\mathrm{n}$ $=1,196)$ and 24 months after the intervention ( $\mathrm{n}=$ $1,296)$. To adjust simultaneously for potential confounders, we performed generalized linear models analysis using PROC GENMOD in SAS (SAS Version 8, SAS Institute Inc., Cary, NC). The following variables were included in regression models: age, sex, race-ethnicity, marital status, smoking status, health insurance, comorbidity (using the Charlson Comorbidity Index), number of chronic illnesses, number of prescribed medications, number of health care visits in the previous year, clinic attended, primary language spoken, family history of targeted cancers, and for women, estrogen replacement therapy and history of benign breast disease. Increasing scores on the Charlson Comorbidity Index reflect a greater burden of comorbid illness. ${ }^{33,34}$

Indicator variables were also created for clinic type (control vs intervention) and for survey year (baseline, or 24-month follow-up). We also included an interaction term for the 2 variables of clinic type and survey year. The interaction term estimates the effect of the intervention controlling for any baseline screening differences and secular trends in screening rates while adjusting for other covariates. Because of the clustered nature of the data, we obtained parameter estimates and $95 \%$ confidence intervals (CIs) using the method of generalized estimating equations. ${ }^{35,36}$ Finally, we repeated our analysis comparing patients who had a Cancer SOS screening checklist in their chart (indicating the intervention had actually been implemented for that patient) with those who did not, to assess the potential effectiveness of the intervention strategy when it was actually implemented. This study was approved by the University of South Florida Institutional Review Board.

\section{RESULTS}

The clinical characteristics of patients attending control clinics compared with those attending intervention clinics have been previously summarized. ${ }^{27}$ Patients attending intervention clinics were more likely to be African American and married and were generally more ill, as evidenced by a greater number of comorbid illnesses, greater number of prescribed medications, and greater number of health care visits. Compliance with the Cancer SOS intervention decreased during the course of the intervention, with 334 of 615 (54.3\%) charts showing evidence of the Cancer SOS cancer screening checklist at a 24-months follow-up, compared with $74 \%$ at the 6 -month follow-up. Cancer screening rates at baseline, 12 months, and 24 months are reported in Table 1 . For all 3 targeted tests, screening differences observed between control and intervention clinics were less prominent at the 24-month follow-up compared with the 12-month follow-up. We

\section{Table 1. Cancer Screening at Baseline, 12 Months', and 24 Months' Follow-up}

\begin{tabular}{lccc}
\hline & \multicolumn{3}{c}{$\begin{array}{c}\text { Percentage of Patients } \\
\text { Up-To-Date }\end{array}$} \\
\cline { 2 - 4 } Variable & Baseline & 12 Months & 24 Months \\
\hline $\begin{array}{l}\text { Papanicolaou smears } \\
\quad \text { Control }\end{array}$ & 57.6 & 48.2 & 45.3 \\
$\quad$ Intervention & 61.9 & 62.4 & 47.3 \\
Mammograms & & & \\
$\quad$ Control & 75.9 & 71.1 & 64.5 \\
Intervention & 71.4 & 75.7 & 67.0 \\
Fecal occult blood tests & & & \\
$\quad$ Total sample & & & \\
$\quad$ Control & 22.1 & 11.9 & 12.6 \\
$\quad$ Intervention & 35.9 & 40.1 & 28.2 \\
Men & & & \\
$\quad$ Control & 22.5 & 12.2 & 11.0 \\
$\quad$ Intervention & 28.3 & 41.4 & 27.3 \\
$\quad$ Women & & & \\
$\quad$ Control & 22.1 & 11.9 & 13.0 \\
Intervention & 38.1 & 39.7 & 28.5 \\
\hline
\end{tabular}




\begin{tabular}{|c|c|c|c|}
\hline Variable & Odds Ratio & $95 \% \mathrm{Cl}$ & $P$ Value \\
\hline Papanicolaou smears $(\mathrm{n}=1,103)$ & 0.88 & $0.68-1.15$ & .34 \\
\hline Mammograms $(n=1,844)$ & 1.26 & $1.02-1.55$ & .03 \\
\hline FOBT $(n=2,009)$ & 1.17 & $0.92-1.48$ & .19 \\
\hline Men & 1.33 & $0.78-2.27$ & .30 \\
\hline Women & 1.13 & $0.87-1.46$ & .37 \\
\hline
\end{tabular}

Some evidence suggests that the decline in effectiveness of the intervention with time was more the result of decreased compliance with the system than then a system that became ineffective with time. For example, compliance with the Cancer SOS system, as determined by the presence of a Cancer SOS screening checklist in the patient's chart, declined from about $75 \%$ at

also assessed the total number of targeted screening tests that were up-to-date. At 24 months, patients in control clinics were, on average, up-to-date on 0.94 cancer screening tests compared with an average of 1.17 tests for patients in intervention clinics $(t$ test $=$ 4.42, $P<.0001)$. Among women who were eligible for all 3 screening tests, the percentage completing screening tests at 24 months was as follows: for the control group, the mean number of tests was $1.22,25.6 \%$ had 0 tests, $34.9 \%$ had 1 test, $31.0 \%$ had 2 tests, and $8.5 \%$ had all 3 tests; for the intervention group, mean number of tests was $1.37,24.0 \%$ had 0 tests, $29.8 \%$ had 1 test, 31.5 had 2 tests, and $14.7 \%$ had all 3 tests.

Multivariate analysis was used to assess the effectiveness of the intervention on individual screening tests by determining the odds ratio for the interaction term previously described (Table 2). The intervention increased the odds of mammography but had no significant effect on the other 2 targeted screening tests. When results were repeated comparing patients having a Cancer SOS screening checklist with those who did not, presence of a checklist was associated with increased odds of Pap smear screening $(\mathrm{OR}=2.03 ; 95 \% \mathrm{CI}, 1.14-3.61 ; \mathrm{P}=$ $.014)$ and FOBT screening $(\mathrm{OR}=3.28 ; 95 \% \mathrm{CI}, 2.05$ 5.23, $P<.0001)$, with a trend of increased odds of mammography screening $(\mathrm{OR}=1.42 ; 95 \% \mathrm{CI}, 0.98-2.07$; $P=.06)$. Finally, in a subgroup analysis, we found no significant difference in the effects of the Cancer SOS intervention among patients having a health maintenance visit (data not shown).

\section{DISCUSSION}

The Cancer SOS intervention had persistent, although modest, effects on screening at 24 months' follow-up. Patients who received care at intervention clinics were up-to-date on a greater number of targeted screening tests at 24 months' follow-up and had $26 \%$ greater odds of mammography screening compared with patients in control clinics. Although still apparent, intervention effects on screening at 24 months' follow-up had clearly diminished relative to effects observed at 12 months follow-up.
6 months' follow-up to just more than $50 \%$ at the 24 month mark. Furthermore, patients having a checklist in the chart had increased odds of screening relative to patients not receiving the intervention.

Although we were unable to assess rigorously the reasons for diminished compliance with the Cancer SOS system, there are several explanations. First, all intervention clinics had some degree of staff turnover during the course of the study. At site visits for data collection, for example, it was not uncommon to find newly hired personnel who were not familiar with the Cancer SOS system. Although the Cancer SOS intervention had provisions for training new staff (training manuals, assigned responsibilities for training, etc), it appeared that training did not always occur in practice. In addition, the enthusiasm with which a new program is implemented would likely diminish as its novelty wanes. Although the Cancer SOS system was purposely designed for ease of implementation and maintenance, it would appear that even such relatively simple interventions as Cancer SOS may require ongoing support from an outside entity to insure full implementation.

Few studies have assessed the durability of office systems interventions. Dietrich and colleagues found that intervention effects on FOBT and self-breast examination persisted 24 months after an office systems intervention was completed but that effects declined for mammography and clinical breast examination. ${ }^{31}$ Margolis and colleagues reported sustained improvements in preventive care for children at 30 months of follow-up with an office systems intervention. ${ }^{37}$ Stange and colleagues also found that improvements in preventive care among intervention clinics were maintained at 24 months' follow-up. ${ }^{38}$ Goodson and colleagues reported some success in the ablility of the clinic to maintain an office intervention even up to 6 years after implementation; effects on screening rates were not reported, however. ${ }^{39}$ While not specifically assessing ongoing effectiveness, other studies have assessed primary outcomes of office systems interventions at a point greater than 12 months after the intervention was implemented. Results were less encouraging in these studies. ${ }^{26,40}$ 
Although a great number of interventions have found significant effects on screening rates in the short term ${ }^{41,42}$ few have proven long-term durability. It is not known whether office systems interventions have better durability than other approaches to improve cancer screening. Improved long-term outcomes (beyond 12 months) have been reported in studies of tailored telephone counseling, for example. ${ }^{43,44}$ Other studies reporting primary outcomes more than 12 months after intervention implementation were not as successful. ${ }^{45-51}$

In conclusion, the Cancer SOS intervention had persistent, although modest, effects on screening at 24 months' follow-up. Effectiveness of the intervention strategy had clearly diminished from results reported at 12 months' follow-up, most likely because of diminished compliance with the system. Further study is needed to develop successful intervention strategies that are either self-sustaining or that are able to produce long-term changes in screening behavior. Cancer SOS materials and methods are freely available for use at the following Web site (http://www.hsc.usf.edu/FAMILY/research/index.htm).

\section{To read or post commentaries in response to this article, see it} online at http://www.annfammed.org/cgi/content/full/3/2/109.

Key words: Mass screening; mammography; vaginal smears; occult blood; breast neoplasms; colorectal neoplasms; community health centers; primary health care

Submitted July 8, 2004; submitted, revised, August 25, 2004; accepted September 8, 2004

Funding support: This research was supported by National Cancer Institute grant R01 CA77282.

\section{References}

1. Miller B, Ries L, Hankey B, Kosary C, Edwards B. Cancer Statistics Review: 1973-1989. Washington, DC: National Cancer Institute; 1992;9. NIH Publication 92-278.

2. Mandelblatt J, Andrews H, Kao R, Wallace R, Kerner J. The late-stage diagnosis of colorectal cancer: demographic and socioeconomic factors. Am J Public Health. 1996;86:1794-1797.

3. Ndubuisi SC, Kofie VY, Andoh JY, Schwartz EM. Black-white differences in the stage at presentation of prostate cancer in the District of Columbia. Urology. 1995;46:71-77.

4. Roetzheim RG, Pal N, Tennant C, et al. Effects of health insurance and race on early detection of cancer. J Natl Cancer Inst. 1999;91:1409-1415.

5. Roetzheim RG, Pal N, Gonzalez EC, Ferrante JM, Van Durme DJ, Krischer JP. Effects of health insurance and race on colorectal cancer treatments and outcomes. Am J Public Health. 2000;90:1746-1754.

6. Roetzheim RG, Gonzalez EC, Ferrante JM, Pal N, Van Durme DJ, Krischer JP. Effects of health insurance and race on breast carcinoma treatments and outcomes. Cancer. 2000;89:2202-2213.

7. Richardson JL, Langholz B, Bernstein L, Burciaga C, Danley K, Ross RK. Stage and delay in breast cancer diagnosis by race, socioeconomic status, age and year. Br J Cancer. 1992;65:922-926.
8. Farley TA, Flannery JT. Late-stage diagnosis of breast cancer in women of lower socioeconomic status: public health implications. Am J Public Health. 1989;79:1508-1512.

9. Wells BL, Horm JW. Stage at diagnosis in breast cancer: race and socioeconomic factors. Am J Public Health. 1992;82:1383-1385.

10. Bassett M, Krieger N. Social class and black-white differences in breast cancer survival. Am J Public Health. 1986;76:1400-1403.

11. Mandelblatt J, Andrews H, Kerner J, Zauber A, Burnett W. Determinants of late stage diagnosis of breast and cervical cancer: the impact of age, race, social class, and hospital type. Am J Public Health. 1991;81:646-649.

12. Hunter C, Redmond C, Chen V, et al. Breast cancer: factors associated with stage at diagnosis in black and white women. J Natl Cancer Inst. 1993;85:1129-1137.

13. Eley JW, Hill HA, Chen VW, et al. Racial differences in survival from breast cancer. Results of the National Cancer Institute Black/White Cancer Survival Study. JAMA. 1994;272:947-954.

14. Ayanian J, Kohler B, Abe T, Epstein A. The relation between health insurance coverage and clinical outcomes among women with breast cancer. N Engl J Med. 1993;329:326-331.

15. Stein J, Fox S. Language preference as an indicator of mammography use among Hispanic women. J Natl Cancer Inst. 1990;82:1715-1716.

16. Calle E, Flanders W, Thun M, Martin L. Demographic predictors of mammography and Pap smear screening in US women. Am J Public Health. 1993;83:53-60.

17. Anderson L, May D. Has the use of cervical, breast, and colorectal cancer screening increased in the United States? Am J Public Health. 1995;85:840-842.

18. Lee J, Vogel V. Who uses screening mammography regularly? Cancer Epidemiol Biomarkers Prev. 1995;4:901-906.

19. Harlan L, Bernstein A, Kessler L. Cervical cancer screening: who is not screened and why? Am J Public Health. 1991;81:885-891.

20. Burns R, McCarthy E, Freund K, et al. Black women receive less mammography even with similar primary care. Ann Intern Med. 1996; $125: 173-182$

21. National Cancer Institute Breast Cancer Screening Consortium. Screening mammography: a missed clinical opportunity? JAMA. 1990;264:54-58.

22. Anonymous. Breast and cervical cancer screening among underserved women. Baseline survey results from six states. The National Cancer Institute Screening Consortium for Underserved Women. Arch Fam Med. 1995;4:617-624.

23. Hayward R, Shapiro M, Freeman H, Corey C. Who gets screened for cervical and breast cancer? Results from a new national survey. Arch Intern Med. 1988:1177-1181.

24. Breen N, Kessler L. Changes in the use of screening mammography: evidence from the 1987 and 1990 National Health Interview Surveys. Am J Public Health. 1994;84:62-67.

25. Dietrich $A, O^{\prime}$ Connor $G$, Keller $A$. Cancer: improving early detection and prevention. Br Med J. 1992;304:687-691.

26. Manfredi C, Czaja R, Freels S, Trubitt M, Warnecke R, Lacey L. Prescribe for health. Improving cancer screening in physician practices serving low-income and minority populations. Arch Fam Med. 1998;7:329-337.

27. Roetzheim $R$, Christman $L$, Jacobsen $P$, et al. A randomized controlled trial to increase cancer screening among attendees of community health centers. Ann Fam Med. 2004;2:294-300.

28. Ornstein S, Garr D, Jenkins R, Rust P, Arnon A. Computer-generated physician and patient reminders: tools to improve population adherence to selected preventive services. J Fam Pract. 1991;32:82-90.

29. Dickey L, Petitti D. A patient-held minirecord to promote adult preventive care. J Fam Pract. 1992;34:457-463. 
30. Dietrich A, Tobin J, Sox C, et al. Cancer early-detection services in community health centers for the underserved: a randomized controlled trial. Arch Fam Med. 1998;7:320-327.

31. Dietrich AJ, Sox CH, Tosteson TD, Woodruff CB. Durability of improved physician early detection of cancer after conclusion of intervention support. Cancer Epidemiol Biomarkers Prev. 1994;3:335-340.

32. Fletcher S, Harris R, Gonzalez J, et al. Increasing mammography utilization: a controlled study. J Natl Cancer Inst. 1993;85:112-120.

33. Charlson M, Pompei P, Ales K, Mackenzie C. A new method of classifying prognostic comorbidity in longitudinal studies: development and validation. J Chron Dis. 1987;40:373-383.

34. Charlson M, Szatrowski T, Peterson J, Gold J. Validation of a combined comorbidity index. J Clin Epidemiol. 1994;47:1245-1251.

35. Liang K, Zeger S. Longitudinal data analysis using generalized linear models. Biometrika. 1986;73:13-22.

36. Liang K, Zeger S. Regression analysis for correlated data. Ann Rev Public Health. 1993;14:43-68.

37. Margolis PA, Lannon CM, Stuart JM, Fried BJ, Keyes-Elstein L, Moore DE Jr. Practice based education to improve delivery systems for prevention in primary care: randomised trial. Br Med J. 2004;328:388.

38. Stange KC, Goodwin MA, Zyzanski SJ, Dietrich AJ. Sustainability of a practice-individualized preventive service delivery intervention. Am J Prev Med. 2003;25:296-300.

39. Goodson P, Murphy Smith M, Evans A, Meyer B, Gottlieb NH. Maintaining prevention in practice: survival of PPIP in primary care settings. Put Prevention Into Practice. Am J Prev Med. 2001;20:184-189.

40. Kinsinger LS, Harris R, Qaqish B, Strecher V, Kaluzny A. Using an office system intervention to increase breast cancer screening. J Gen Intern Med. 1998;13:507-514.

41. Stone EG, Morton SC, Hulscher ME, et al. Interventions that increase use of adult immunization and cancer screening services: a metaanalysis. Ann Intern Med. 2002;136:641-651.
42. Mandelblatt J, Kanelsky P. Effectiveness of interventions to enhance physician screening for breast cancer. J Fam Pract. 1995;40:162-171.

43. Lauver DR, Settersten L, Kane JH, Henriques JB. Tailored messages, external barriers, and women's utilization of professional breast cancer screening over time. Cancer. 2003;97:2724-2735.

44. Valanis $B$, Whitlock EE, Mullooly J, et al. Screening rarely screened women: time-to-service and 24-month outcomes of tailored interventions. Prev Med. 2003;37:442-450.

45. Zhu K, Hunter S, Bernard LJ, et al. An intervention study on screening for breast cancer among single African-American women aged 65 and older. Prev Med. 2002;34:536-545.

46. Zapka JG, Costanza ME, Harris DR, et al. Impact of a breast cancer screening community intervention. Prev Med. 1993;22:34-53.

47. Allen JD, Stoddard AM, Mays J, Sorensen G. Promoting breast and cervical cancer screening at the workplace: results from the Woman to Woman Study. Am J Public Health. 2001;91:584-590.

48. Kim CS, Kristopaitis RJ, Stone E, Pelter M, Sandhu M, Weingarten SR. Physician education and report cards: do they make the grade? Results from a randomized controlled trial. Am J Med. 1999;107:556560.

49. Hillman AL, Ripley K, Goldfarb N, Nuamah I, Weiner J, Lusk E. Physician financial incentives and feedback: failure to increase cancer screening in Medicaid managed care. Am J Public Health. 1998;88:1699-1701.

50. Rimer BK, Conaway M, Lyna P, et al. The impact of tailored interventions on a community health center population. Patient Educ Couns. 1999;37:125-140.

51. Messina CR, Lane DS, Grimson R. Effectiveness of women's telephone counseling and physician education to improve mammography screening among women who underuse mammography. Ann Behav Med. 2002;24:279-289. 